\title{
Sedimentary records of MIF-S and redox-sensitive elements indicate the oxygenated early Earth \\ HIROSHI OHMOTO
}

Penn State University

Presenting Author: hqo@psu.edu

The presence of MIF-S and the low contents of Mo and U in many (not all) Archean-aged sedimentary rocks have been widely considered as "definitive evidence" for an anoxic early Earth. However, the paradigm for MIF-S is questionable because: (a) MIF-S has been found in some recent volcanic ashes, aerosols from coal-burning, and in some post-Archean sedimentary rocks and ore deposits; (b) some products of photochemical- and chemisorption experiments, carried out in $\mathrm{O}_{2}$-rich atmospheres, show MIF-S; and (c) the likeliness that, throughout the geologic history, $\mathrm{SO}_{2}$ from explosive volcanism originated from seawater $\mathrm{SO}_{4}{ }^{2-}$ that was produced mostly by the oxidative weathering of pyrite (Ohmoto, 2020). Considering these, here I propose that the MIF-S in Archean and younger materials were produced mostly by: (i) UV photolysis of volcanic $\mathrm{SO}_{2}$ in an $\mathrm{O}_{2}$-rich stratosphere (i.e., above the $\mathrm{UV}$ shield) over an $\mathrm{O}_{2}$-rich troposphere and (ii) thermochemical $\mathrm{SO}_{4}^{2-}$ reduction by organic matter in sediments.

Mo and $U$ contents of ancient shales have been used by previous researchers as accurate measures of $p \mathrm{O}_{2}$ of the contemporaneous atmosphere. However, they have neglected the facts that: (1) more than $\sim 50 \%$ of the Proterozoic and Phanerozoic shales, deposited under $\mathrm{O}_{2}$-rich atmospheres, have the same Mo and U contents as the Archean shales; (2) nearly all Archean-aged sedimentary rocks have been subjected to highgrade metamorphism, resulting in the losses of $>50 \%$ of the original contents of organic matter and associated elements (Mo, $U$ etc.); and (3) losses of $U$ by radioactive decay. Here I suggest a new method to estimate the contents of redox-sensitive elements in ancient oceans by examining the concentration ratios of redox-sensitive elements to least mobile lithophile elements, such as $\mathrm{Mo} / \mathrm{Zr}$ and $\mathrm{U} / \mathrm{Ti}$, in sedimentary rocks. My analyses of trace element data on cherts and shales of various geologic ages indicate that the contents of Mo, $\mathrm{U}$ and $\mathrm{W}$ in the oceans, therefore the atmospheric $p \mathrm{O}_{2}$ levels, have been essentially the same as today since at least $\sim 3.5 \mathrm{Ga}$ ago. 